\title{
Mensaje de la presidenta de la Confederación Académica Nipona, Española y Latinoamericana por el $\mathbf{3 0}$ Aniversario de fundación
}

Estimados lectores:

Nuestra revista anual Cuadernos CANELA es el eslabón de esta Confederación Académica Nipona, Española y Latinoamericana, que vio su luz el primer volúmen en 1989. Inició como el acta de las ponencias presentadas en el congreso y tras cumplir los 25 años de fundación, la revista dio un salto con el vol. 26 publicado en 2015 y se convirtió en una publicación de particiación abierta de divulgación científica internacional.

Los temas que abarcamos en la revista son: literatura, pensamiento, historia, fenómenos sociológicos, lingüística y metodología de la enseñanza del español como lengua extranjera, aportando perspectivas nuevas, fruto de investigaciones profundas, de estudios comparativos con la literatura japonesa, de la traducción literaria, de la filosofía zen y el arte japonés, de la indagación de la documentación histórica en los archivos, de estudios sociales con un especial interés en la inmigración, del análisis lingüístico y gramatical, de la observación comparativa de las lenguas, de la experiencia didáctica en las aulas universitarias de Japón, y las propuestas metodológicas para mejorar el aprendizaje del idioma, entre otros temas. El equipo editorial ha sido estricto y exigiente con los autores para mantener y mejorar la calidad de la revista. Como resultado de ello, obtuvimos la subvención del programa «Baltasar Gracián» del Ministerio de Eucación, Cultura y Deportes de España a partir del año 2002 hasta el 2011, año que se retiró el mismo programa.

La tarea editorial también ha evolucionado. Hasta el vol. 14 (2002) la labor se hacía con el procesador de palabras y los preparativos de la edición han sido posibles por uno de los fundadores, Noburo Kinoshita, y miembros como Testuya Sumita, Yukari Ito, Midori Asawaka - que en paz descanse-, quienes sacrificaron cada año sus vacaciones para la labor editorial. A partir del vol. 15 (2003), los jefes de sección se incorporaron al equipo editorial. El uso del programa Microsoft Office y el correo electrónico nos ahorraron muchas de las labores editoriales. La creación de la página web y el acceso a la revista en línea a cargo de Arturo Escandón bajo la presidencia de Hilario Kopp impulsó la divulgación de CANELA y su Cuadernos. Con el vol. XXIII (2013) se agregó el perfil de autor y con el vol. XXV (2015) se exigió incluir un resúmen en japonés, labor para la cual contamos con la colaboración para la traducción de miembros como Masami Ogawa y Keishi Yasuda. Se 
mejoró también la presentación con la editora Analía Vitale (2011-2012), adoptando el estilo APA, exigiendo de esta manera mayor calidad. Y es bajo la presidencia de Arturo Escandón (2013-2016) que se creó una comisión científica y una red de evaluadores pares, contando así con el asesoramiento y calificación de investigadores de primera línea a nivel internacional. Es en este periodo que la editora María Fernández introdujo, además, el Open Journal System para la edición de Cuadernos CANELA, facilitando aún más esta labor.

Son notorias la variedad y la originalidad en las investigaciones aquí reunidas. Prueba de ello es que muchos de los miembros han recibido el título de doctor o están por titularse. Esto es uno de los logros académicos de esta confederación, de ser competentes en cada una de nuestras áreas y no limitarnos por encontrarnos en un país que no es originalmente de habla hispana, como es el caso de Japón. Esperamos así que nuestra contribución académica siga enriqueciendo nuestros lazos académicos sin diferencia de nacionalidades de aquí en adelante. 